\title{
Correction to: Association among dispositional mindfulness, self-compassion, and leukocyte telomere length in Chinese adults
}

\author{
Shian-Ling Keng ${ }^{1 *}$, Onn Siong Yim², Poh San Lai ${ }^{2}$, Soo Hong Chew ${ }^{3}$ and Richard P. Ebstein ${ }^{4^{*}}$
}

\section{Correction to: BMC Psychol 7, 47 (2019) https://doi.org/10.1186/s40359-019-0323-y}

Following publication of the original article [1], the authors reported an error in coding of the Isolation subscale of the Self-Compassion Scale.

Namely, the mean score for SCS-Isolation reported in Table 2 should be 2.79 ( $\mathrm{SD}=.91)$. Following this correction, the mean score of the overall SCS scale should be $2.96(\mathrm{SD}=.59)$.

Re-analyses using the newly computed scores showed there was a trend for self-compassion to be positively associated with leukocyte telomere length (LTL), $\beta=.13, \Delta R^{2}=.02, p=.10$. The trend remains after including age as a covariate in the analyses, $\beta=.13, \Delta R^{2}=.02, p=.09$. The association between the isolation subscale and LTL remained insignificant (with or without including age as a covariate) following the re-analyses.

The authors thank you for reading this correction and apologize for any inconvenience caused.

Author details

'Division of Social Science, Yale-NUS College, 16 College Ave West, \#01-220, Singapore 138527, Singapore. ${ }^{2}$ Department of Paediatrics, National University of Singapore, 21 Lower Kent Ridge Rd, Singapore 119077, Singapore.
${ }^{3}$ Department of Economics, National University of Singapore, 21 Lower Kent Ridge Rd, Singapore 119077, Singapore. ${ }^{4}$ China Center for Behavior Economics and Finance, South Western University of Finance and Economics, Chengdu, China.

Published online: 22 June 2020

Reference

1. Keng S, Yim OS, Lai PS, et al. Association among dispositional mindfulness, self-compassion, and leukocyte telomere length in Chinese adults. BMC Psychol. 2019;7:47 https://doi.org/10.1186/s40359-019-0323-y.

*Correspondence: kengsl@yale-nus.edu.sg; rpebstein@gmail.com

'Division of Social Science, Yale-NUS College, 16 College Ave West, \#01-220, Singapore 138527, Singapore

${ }^{4}$ China Center for Behavior Economics and Finance, South Western University of Finance and Economics, Chengdu, China

Full list of author information is available at the end of the article

C C The Author(s). 2020 Open Access This article is licensed under a Creative Commons Attribution 4.0 International License, which permits use, sharing, adaptation, distribution and reproduction in any medium or format, as long as you give appropriate credit to the original author(s) and the source, provide a link to the Creative Commons licence, and indicate if changes were made. The images or other third party material in this article are included in the article's Creative Commons licence, unless indicated otherwise in a credit line to the material. If material is not included in the article's Creative Commons licence and your intended use is not permitted by statutory regulation or exceeds the permitted use, you will need to obtain permission directly from the copyright holder. To view a copy of this licence, visit http://creativecommons.org/licenses/by/4.0/ The Creative Commons Public Domain Dedication waiver (http://creativecommons.org/publicdomain/zero/1.0/) applies to the data made available in this article, unless otherwise stated in a credit line to the data. 